\title{
Doses de nitrogênio no acúmulo de nitrato e na produção da alface em hidroponia
}

\author{
Mônica LA Pôrto'; Jailson do C Alves²; Adailson P de Souza³; Raunira da C Araújo³; Jandeilson A de \\ Arruda $^{4}$; Ubaldo A Tompson Júnior ${ }^{3}$ \\ ${ }^{1}$ UFV, Depto. Fitotecnia, Av. P.H. Rolfs s/n, 36570-000 Viçosa-MG; monicalporto@yahoo.com.br; ${ }^{2}$ IFAL, Campus avançado Santana \\ do Ipanema, Rod. BR 316, km 87,5, 57500-000 Santana do Ipanema-AL; jailson.alves@ifal.edu.br; ${ }^{3}$ UFPB, Depto. Solos e Eng. Rural, \\ 58397-000 Areia-PB, Campus Picuí; adailson@cca.ufpb.br; raunira@cft.ufpb.br; tompsonjunior@yahoo.com.br; ${ }^{4} \mathrm{IFPB}, \mathrm{Campus}$ Picui, \\ Rod. PB 151 s/n, 58187-000 Picuí-PB; jandeilson_agro@hotmail.com
}

\section{RESUMO}

A produção da alface em hidroponia apresenta crescente expansão no Brasil, mas ainda ocorrem problemas de qualidade e risco de acúmulo de nitrato. O objetivo desse trabalho foi avaliar a produção da alface (cv. Elba) e acúmulo de nitrato em hidroponia em função de níveis crescentes de $\mathrm{N}$ na solução nutritiva. Plantas de alface foram cultivadas em estufa telada da UFPB em Areia (PB), em solução nutritiva que continha níveis crescentes de $\mathrm{N}(11,13$, $15,17,19$ e $21 \mathrm{mmol} \mathrm{L}^{-1}$ ) por 25 dias. O delineamento utilizado foi inteiramente casualizado com quatro repetições. Foram avaliadas a produção total (PTT), produção comercial (PCM) e os teores de nitrato na matéria fresca da raiz, caule e folhas da alface. Não foram verificados efeitos significativos do incremento dos níveis de $\mathrm{N}$ na solução sobre a PTT e PCM, sendo obtidos valores médios de 357,3 e 352,5 g/planta, respectivamente. A elevação dos níveis de $\mathrm{N}$ em solução resultou em incrementos nos teores de nitrato em todas as partes da alface, obtendo-se na dose máxima teores de 659, 623 e 615 $\mathrm{mg} \mathrm{kg}^{-1}$ de matéria fresca, para raiz, caule e folhas, respectivamente. Os máximos teores foliares de nitrato obtidos se encontraram abaixo do limite de risco para saúde humana.

Palavras-chave: Lactuca sativa, solução nutritiva, qualidade nutricional.

\begin{abstract}
Nitrogen rates on nitrate accumulation and lettuce production in hydroponic system

Lettuce production in hydroponic system presents growing expansion in Brazil, but still there are problems of quality and risk of nitrate accumulation. This work was carried out to evaluate the lettuce production and nitrate accumulation in hydroponic system depending on the increasing levels of nitrogen in the nutrient solution. The experiment was conducted in greenhouse of the Universidade Federal da Paraíba, Brazil. The lettuce plants were grown in nutrient solution containing increasing levels of $\mathrm{N}(11,13,15,17,19$ and 21 mmol L $\mathrm{L}^{-1}$ ) during a 25-day period. An entirely randomized design with four replications was used. Plant total yield (PTT), plant commercial yield (PCM) and nitrate contents in the fresh matter of roots, stems and leaves of the lettuce were evaluated. There were no significant effects of increasing levels of $\mathrm{N}$ in nutrient solution on PTT and PCM, average values of 357.3 and $352.5 \mathrm{~g} / \mathrm{plant}$ being observed, respectively. The increased levels of $\mathrm{N}$ in nutrient solution increased linearly nitrate content on all lettuce parts. The nitrate content reached 659,623 and $615 \mathrm{mg} / \mathrm{kg}$ in the fresh matter of roots, stems and leaves, respectively, at the highest $\mathrm{N}$ level. Nevertheless, the maximum nitrate content observed in leaves was far below the risk level for human health.
\end{abstract}

Keywords: Lactuca sativa, nutrient solution, nutritional quality.

(Recebido para publicação em 1 de abril de 2011; aceito em 30 de julho de 2012)

(Received on April 1, 2011; accepted on July 30, 2012)

$\mathrm{D}$ entre as hortaliças, a alface (Lactuca sativa) se destaca como uma das mais produzidas e comercializadas no Brasil, apresentando-se como uma das mais populares na mesa do brasileiro. Essa cultura pode ser explorada em diferentes sistemas de cultivo, como convencional, orgânico e hidropônico, sendo sua comercialização realizada desde feiras livres até os grandes centros comerciais, o que lhe assegura uma expressiva importância social e econômica (Krohn et al., 2003; Pôrto, 2006; Pôrto et al., 2008).

A alface é uma das hortaliças mais difundida entre os produtores hidropônicos, provavelmente devido ao seu pioneirismo como cultura hidropônica no país, bem como por se tratar de uma cultura de fácil manejo e principalmente por apresentar um ciclo curto (Fernandes et al., 2002; Lopes et al., 2003; Gualberto et al., 2009). São inúmeras as vantagens apresentadas para o cultivo hidropônico da alface em relação aos demais sistemas de cultivo, tais como utilização de pequenas áreas, economia de água, automação, redução drástica do uso de defensivos, maior controle da nutrição das plantas, encurtamento do ciclo da planta e ante- cipação da colheita, produção durante o ano todo, maior produtividade, rápido retorno econômico, produção fora de época, melhores preços e melhor qualidade (Faquin et al., 1996; Bernardes, 1997; Faquin \& Andrade, 2004).

A qualidade dos alimentos é muito importante, principalmente no caso das hortaliças que são geralmente consumidas in natura. O acúmulo de nitrato nos alimentos é um problema que tem chamando atenção de muitos pesquisadores há algum tempo, pois esse composto quando ingerido em grandes quantidades pelo homem pode causar 
graves conseqüências à saúde, como formação de nitrosaminas, substância potencialmente carcinogênica, além da metahemoglobinemia ou "sangue azul" que reduz o transporte de oxigênio no sangue (Boink \& Speijers, 2001; Addiscott \& Benjamin, 2004; Pôrto et al., 2008). As hortaliças, juntamente com água potável, representam as principais fontes de nitrato para o organismo humano (Ohse et al., 2002). Algumas estimativas apontam que as hortaliças correspondem ao grupo de alimentos que mais contribui para a ingestão de nitrato pelo homem, sendo responsáveis por cerca 72 e 94\% da ingestão diária (Turazi et al., 2006; Takahashi et al., 2007).

$\mathrm{O}$ acúmulo de nitrato nas plantas depende de diversos fatores como aqueles inerentes à cultura (caráter genético, espécies, cultivares e órgão analisado), fatores ambientais (intensidade luminosa, temperatura, época de cultivo ou estação do ano, etc), horário de colheita (manhã, tarde e noite); sistema de cultivo (convencional, orgânico e hidropônico) e adubação (manejo, quantidade e tipo de fertilizantes nitrogenados) (Krohn et al., 2003; Cometti et al., 2004; Faquin \& Andrade, 2004; Pôrto et al., 2008). Juntamente com a intensidade luminosa, a disponibilidade de nitrogênio é o fator que mais exerce influência no acúmulo de nitrato pelas plantas. Assim, níveis excessivos de $\mathrm{N}$ através da utilização de fertilizantes minerais, orgânicos ou na composição de soluções nutritivas, irão ocasionar problemas de acúmulo de nitrato nas plantas.

Muitos questionamentos vêm sendo levantados com relação ao risco do acúmulo de nitrato nas hortaliças oriundas de cultivo hidropônico. Em geral, sabe-se que a alface hidropônica apresenta teores de nitrato superiores aos da alface produzida em sistema orgânico e convencional (Beninni et al., 2002; Cometti et al., 2004), o que pode ser justificado pelo fato das soluções nutritivas usadas em hidroponia apresentarem alta disponibilidade de nitrato, levando consequentemente ao seu maior acúmulo em plantas cultivadas nessas condições (Faquin et al., 1996; Faquin \& Andrade, 2004). Entretanto, trabalhos recentes têm apontado que os teores de nitrato verificados para a alface produzida em cultivo hidropônico estão frequentemente abaixo dos limites máximos permitidos pela comunidade européia para alface produzida em ambiente protegido, que são de 3,5 a 4,5 g $\mathrm{kg}^{-1}$ (Van Der Boon et al., 1990; Faquin et al., 1996; Cometti et al., 2004; Faquin \& Andrade, 2004).

Apesar da relevância do assunto, estudos sobre a produção hidropônica da alface, principalmente no que diz respeito ao manejo da disponibilidade de $\mathrm{N}$ na solução nutritiva, ainda são bastante escassos para as condições regionais do Nordeste brasileiro. Assim, o objetivo desse trabalho foi avaliar produção da alface e acúmulo de nitrato em hidroponia em função de níveis crescentes de N na solução nutritiva em Areia-PB.

\section{MATERIAL E MÉTODOS}

O presente trabalho foi conduzido em estufa telada da UFPB em Areia (PB), nos meses de março a abril de 2005, utilizando plantas de alface (cv. Elba, crespa solta), cultivadas em hidroponia estática.

No período de realização do experimento, verificaram-se os valores climáticos médios, em março: temperatura mínima $21,7^{\circ} \mathrm{C}$ fora e $26,1^{\circ} \mathrm{C}$ dentro da estufa de cultivo; temperatura máxima $30,8^{\circ} \mathrm{C}$ fora e $34,1^{\circ} \mathrm{C}$ dentro da estufa de cultivo; e umidade relativa do ar $74,9 \%$ fora e $55,6 \%$ dentro da estufa de cultivo; mês de abril: temperatura mínima $21,4^{\circ} \mathrm{C}$ fora e $26,9^{\circ} \mathrm{C}$ dentro da estufa de cultivo; temperatura máxima $29,0^{\circ} \mathrm{C}$ fora e $33,8^{\circ} \mathrm{C}$ dentro da estufa de cultivo; e umidade relativa do ar 77,2\% fora e $61,4 \%$ dentro da estufa de cultivo.

A alface foi semeada em 12/03/05, em copos plásticos de $50 \mathrm{~mL}$ (furados na base), utilizando como substrato areia lavada. Colocaram-se cinco sementes por copinho, sendo que aos cinco dias após a germinação efetuou-se o desbaste, deixando uma muda por copo. A irrigação das mudas seguiu o seguinte esquema: da semeadura até os cinco dias após a emergência, as mudas foram irrigadas apenas com água deionizada; dos cinco aos 10 dias após a emergência, as mudas foram irrigadas com solução nutritiva a $25 \%$ da força iônica; dos 10 aos 15 dias após a emergência, as mudas foram irrigadas com a solução nutritiva a 50\% da força iônica; dos 16 dias até o transplante (21 dias após a germinação), as mudas foram irrigadas com a solução nutritiva com $75 \%$ da força iônica. As mudas foram irrigadas com solução de Hoagland (Hoagland \& Arnon, 1938). Aos 21 dias da germinação (02/04/05), quando as mudas atingiram o estádio de quatro a cinco folhas definitivas, elas foram transplantadas para o local de crescimento.

O delineamento experimental utilizado foi inteiramente casualizado, com cinco tratamentos e quatro repetições. A parcela experimental constou de um vaso, contendo duas plantas. As plantas foram cultivadas em vasos plásticos, revestidos com sacos plásticos em seu interior, que continham 5,5 L de solução nutritiva, modificada a partir da solução de Hoagland (Hoagland \& Arnon, 1938), com as seguintes concentrações de N: $11,13,15,17,19$ e $21 \mathrm{mmol} \mathrm{L}^{-1}$ (154, 182, 210, 238, 266 e $294 \mathrm{mg} \mathrm{L}^{-1}$ de N). Na formulação da solução nutritiva, foram empregadas as seguintes fontes de nutrientes: $\mathrm{NH}_{4} \mathrm{H}-$ ${ }_{2} \mathrm{PO}_{4}, \mathrm{MgSO}_{4} .7 \mathrm{H}_{2} \mathrm{O}, \mathrm{Ca}\left(\mathrm{NO}_{3}\right)_{2} \cdot 4 \mathrm{H}_{2} \mathrm{O}$, $\mathrm{KCl}, \mathrm{KNO}_{3}, \mathrm{NH}_{4} \mathrm{NO}_{3}, \mathrm{NaNO}_{3}, \mathrm{H}_{3} \mathrm{BO}_{3}$, $\mathrm{CuSO}_{4} .5 \mathrm{H}_{2} \mathrm{O}, \mathrm{FeCl}_{3}+\mathrm{Na}_{2}$ EDTA, $\mathrm{MnSO}_{4}$. $\mathrm{H}_{2} \mathrm{O},\left(\mathrm{NH}_{4}\right)_{6} \mathrm{Mo}_{7} \mathrm{O}_{24} \cdot 4 \mathrm{H}_{2} \mathrm{O}$ e $\mathrm{ZnSO}_{4} \cdot 7 \mathrm{H}_{2} \mathrm{O}$.

Os vasos foram tampados com tampas de isopor revestidas de papel alumínio, perfuradas no centro para dar suporte às mudas, sendo conduzida uma planta por vaso.

A solução nutritiva foi preparada utilizando água deionizada e reagentes P.A., sendo a mesma mantida em aeração constante, mediante injeção forçada de ar por um compressor. $\mathrm{O}$ volume dos vasos foi completado, sempre que necessário, utilizando-se também água deionizada. $\mathrm{O}$ pH da solução foi monitorado diariamente, sendo mantido na fai-

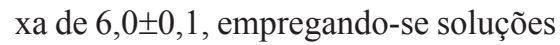
diluídas $(0,1 \mathrm{M})$ de $\mathrm{HCl}$ ou $\mathrm{NaOH}$, para reduzir ou elevar o $\mathrm{pH}$, respectivamente. Durante o transcorrer do experimento, procedeu-se ainda o monitoramento periódico da condutividade elétrica (CE) da solução nutritiva, sendo realizada a troca da solução sempre que houve um decréscimo de $25 \%$ na $\mathrm{CE}$ em relação ao valor inicial. 
A colheita foi realizada aos 25 dias após o transplante (27/04/05), quando as plantas apresentavam características comerciais, sendo efetuada no final da tarde $( \pm 17 \mathrm{hs})$. As plantas colhidas foram acondicionadas em sacos plásticos e transportadas até o laboratório de análises de tecido vegetal da UFPB para que se procedessem as analises.

A produção total (PTT) (produção total de matéria fresca da parte aérea (caule + folhas)) e produção comercial (PCM) (produção de matéria fresca da parte aérea (caule + folhas)), menos as folhas amarelecidas, secas e, ou, atacadas por pragas e doenças) da alface foram determinadas em balança analítica de precisão.

Posteriormente, amostras de raiz, caule e folhas da alface foram lavadas em água de torneira e, posteriormente, em água deionizada. Em seguida, as amostras foram pesadas e colocadas para secar em estufa de circulação forçada de ar $\left(65^{\circ} \mathrm{C}\right)$, até atingirem peso constante, obtendo-se o teor de matéria seca. Posteriormente, as amostras foram trituradas em moinho de facas e tamisadas em peneira de 20 mesh. Os teores de nitrato na matéria seca das diferentes partes (raiz, caule e folhas) da alface foram determinados empregando o método do ácido salicílico proposto por Cataldo et al. (1975). Com base nos teores de matéria seca das diferentes partes da alface, os teores de nitrato na matéria seca foram convertidos para teores na matéria fresca.

Os resultados obtidos foram submetidos a análises de variância, com desdobramento do efeito quantitativo dos níveis de $\mathrm{N}$ em regressões, empregando o nível de significância de até $5 \%$. Todas as análises estatísticas foram realizadas utilizando o software SAEG, versão 9.1 (SAEG, 2007).

\section{RESULTADOS E DISCUSSÃO}

Os resultados encontrados neste trabalho demonstram-se satisfatórios, estando dentro do padrão de produção encontrados por outros autores para a cv. Elba em hidroponia (Casaroli et al., 2003; Gualberto et al., 2009), apresentando média de produção em torno de 300 a 400 g/planta de matéria fresca da parte aérea. Entretanto, não houve efeitos significativos do incremento dos níveis de $\mathrm{N}$ na solução nutritiva sobre a produção total (PTT) e produção comercial (PCM) da alface, verificando-se valores médios de 357,3 e 352,5 g/ planta, respectivamente.

Muito embora a alface, por se tratar de uma hortaliça folhosa, responda muito bem em termos produtivos ao fornecimento de $\mathrm{N}$, proporcionando maiores rendimentos, produção mais uniforme e de maior valor comercial (Filgueira, 2008), a falta de resposta observada neste trabalho deve está relacionada aos níveis de $\mathrm{N}$ empregados na solução nutritiva, que estão dentro da faixa recomendada para o cultivo da alface em hidroponia $(7,14$ a 21,42 mmol L-1 ou 100 a $300 \mathrm{mg} \mathrm{L}^{-1}$ ) (Bernardes, 1997). Isso mostra que mesmo os menores níveis desse nutriente usados no ensaio foram suficientes para atender as exigências da cultura. Entretanto, é importante mencionar que na prática alguns produtores tem empregado doses de $\mathrm{N}$ superiores às empregadas nesse experimento $\left(21,42\right.$ a $28,57 \mathrm{mmol} \mathrm{L}^{-1}$ de $\mathrm{N}$

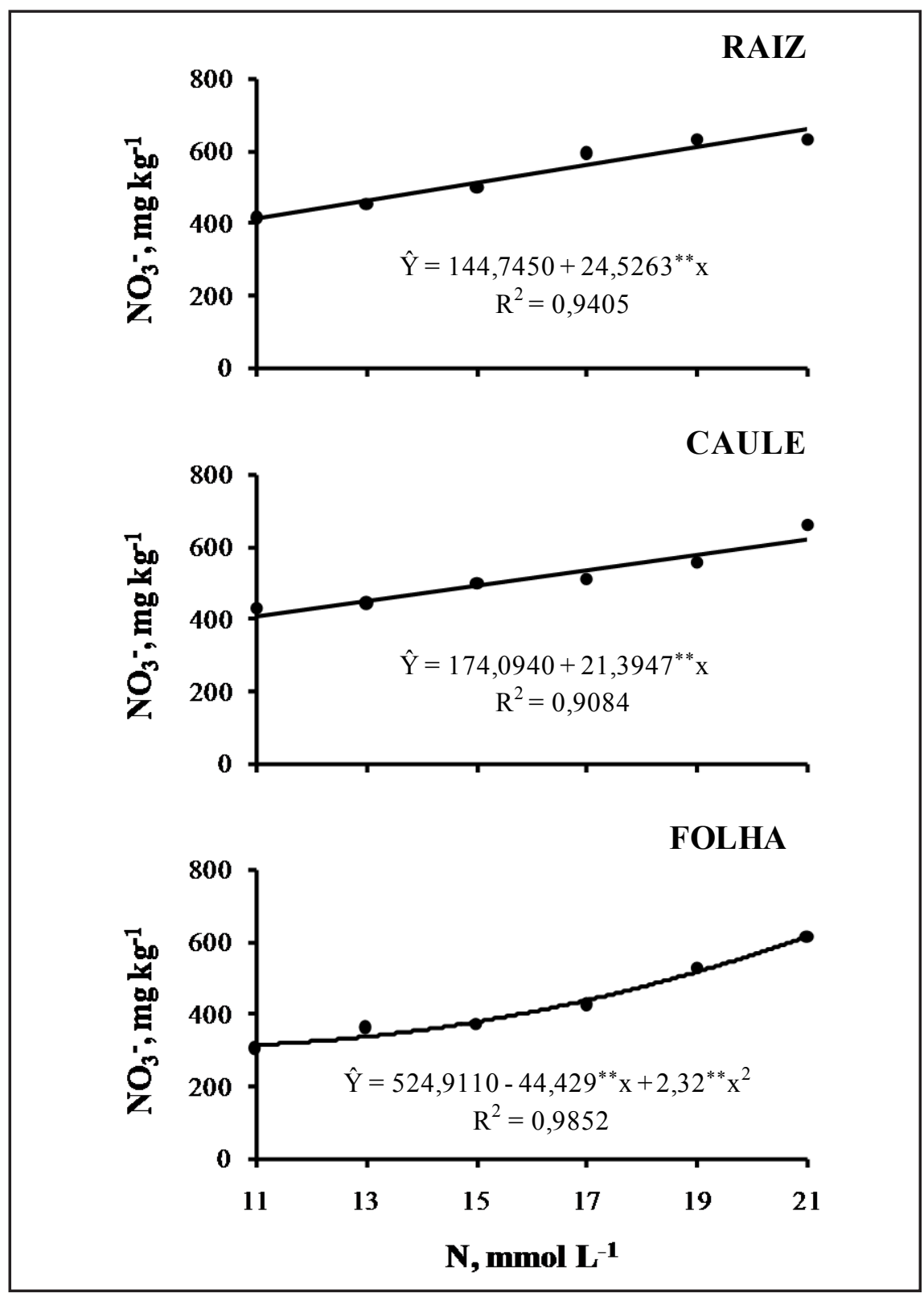

Figura 1. Teores de nitrato $\left(\mathrm{NO}_{3}^{-}\right)$na matéria fresca da raíz, caule e folha da alface hidropônica (cv. Elba) em função de doses crescentes de $\mathrm{N}$ na solução nutritiva (nitrate contents $\left(\mathrm{NO}_{3}^{-}\right)$ on fresh matter of roots, stems and leaves of hydroponic lettuce depending on increasing levels of $\mathrm{N}$ in the nutrient solution). Areia, UFPB, 2005. 
ou 300 a $400 \mathrm{mg} \mathrm{L}^{-1}$ de N), o que poderia resultar em influência significativa sobre as características produtivas da alface.

Como o experimento foi realizado em uma época do ano bastante quente na região (março a abril) e a estufa de cultivo não era climatizada, as condições de elevada intensidade de radiação solar e, principalmente, a elevada temperatura do ar (em vários momentos superiores a $30^{\circ} \mathrm{C}$ ) no interior da estufa de produção durante o período de cultivo também podem ter influenciado na falta de resposta da alface aos níveis crescentes de N. Wien (1997) destaca que a variação ótima de temperatura para o cultivo da alface é de 4 a $27^{\circ} \mathrm{C}$, sendo que temperaturas superiores à máxima tolerada são bastante prejudiciais à produtividade da cultura. Caron et al. (2003) destacam que o excesso de radiação pode ser prejudicial ao acúmulo de fitomassa e ao crescimento da alface, pois as folhas podem atingir o ponto de saturação de luz e diminuir a conversão de energia solar em energia química. Andriolo (2000) relata que alta radiação solar, associada à alta temperatura, pode resultar em degradação dos pigmentos de clorofila, redução da fotoassimilação de carboidratos e aumento da respiração da planta, consequentemente, desacelerando o crescimento e diminuindo o acúmulo de fitomassa.

A elevação dos níveis de $\mathrm{N}$ em solução resultou em incremento nos teores de nitrato nas diferentes partes da alface, apresentando comportamento linear na raiz e caule, e quadrático para as folhas, sendo verificado no nível máximo de $\mathrm{N}$ teores de 659,80, 623,38 e 615,02 $\mathrm{mg} \mathrm{kg}^{-1}$ de matéria fresca na raiz, caule e folhas, respectivamente (Figura 1). Esses resultados demonstram que a elevação na disponibilidade de $\mathrm{N}$ é um fator preponderante para o acúmulo de nitrato pelas plantas, reforçando o proposto na literatura por diversos autores (Chen et al., 2004; Gülser, 2005; Mantovani et al., 2005; Turan \& Sevimli, 2005; Pôrto et al., 2008). De acordo com Marschner (1995), o acúmulo de nitrato pelas plantas ocorre quando há excesso de absorção de nitrogênio em relação à capacidade de assimilação deste nutriente, uma vez que havendo $\mathrm{N}$ disponível no sistema para absorção a planta tende a absorvê-lo além de sua demanda e estocá-lo nos vacúolos na forma de nitrato.

Para ser metabolizado pelas plantas (incorporado a compostos orgânicos, como aminoácidos, proteínas e outros compostos nitrogenados), o nitrato $\left(\mathrm{NO}_{3}^{-}\right)$absorvido deve ser necessariamente reduzido para amônio $\left(\mathrm{NH}_{4}^{+}\right)$. Esta redução ocorre em duas etapas: a primeira no citoplasma, onde o nitrato $\left(\mathrm{NO}_{3}^{-}\right)$é convertido a nitrito $\left(\mathrm{NO}_{2}^{-}\right)$, através da ação da enzima redutase do nitrato; a segunda nos cloroplastos, onde o nitrito $\left(\mathrm{NO}_{2}^{-}\right)$é convertido a amônio $\left(\mathrm{NH}_{4}^{+}\right)$, pela ação da enzima redutase do nitrito. Na primeira etapa, o agente redutor é o NADH (originado na respiração), e na segunda etapa o agente redutor é a ferredoxina reduzida (cujos elétrons são originados no fotossistema I (FSI) da fase clara da fotossíntese) (Faquin \& Andrade, 2004). Em situação de elevada disponibilidade de $\mathrm{N}$, tende a ocorrer alto influxo de nitrato, o que pode resultar em déficit de poder redutor (proveniente do NADH e da ferredoxina reduzida) para redução e assimilação desse ânion, o que resulta, consequentemente, em seu maior acúmulo pelas plantas (Cometti et al., 2004).

Em trabalho realizado também com a cv. Elba, na mesma região e mesmo período de cultivo do presente experimento, Pôrto et al. (2008) verificaram teores de nitrato nas diferentes partes da alface inferiores aos observados neste trabalho, para alface produzida em solo com o emprego de doses crescentes de esterco bovino ( 0 a $\left.150 \mathrm{t} \mathrm{ha}^{-1}\right)$ e uréia ( 0 a $150 \mathrm{~kg} \mathrm{ha}^{-1} \mathrm{de} \mathrm{N}$ ), onde foram obtidos teores máximos de nitrato de 65,09 e 93,96 $\mathrm{mg} \mathrm{kg}^{-1}$ na raiz; 98,22 e 183,45 $\mathrm{mg} \mathrm{kg}^{-1}$ no caule; e 75,62 e121,98 mg $\mathrm{kg}^{-1}$ nas folhas, para a adubação orgânica e nitrogenada, respectivamente. Outros autores também têm relatado o fato de que a alface produzida em hidroponia tende a apresentar maiores teores de nitrato em relação à alface produzida em sistemas orgânico e convencional (Beninni et al., 2002; Cometti et al., 2004; Favaro-Trindade et $a l ., 2007)$, o que pode ser justificado pelo fato das soluções nutritivas empregadas em hidroponia apresentarem alta disponibilidade de nitrato, levando consequentemente ao seu maior acúmulo em plantas cultivadas nessas condições (Faquin et al., 1996; Faquin \& Andrade 2004).

Entretanto, é importante ressaltar que os máximos teores de nitrato obtidos nas diferentes partes da alface no presente estudo são inferiores aos observados por outros autores para alface produzida em hidroponia (Beninni et al., 2002; Fernandes et al., 2002; Cometti et al., 2004; Favaro-Trindade et al., 2007; Takahashi et al., 2007), o que pode ser atribuído às condições em que esse trabalho foi conduzido (elevada intensidade luminosa) e horário de coleta empregado (final da tarde), fatores que contribuem para reduzir o acúmulo de nitrato pelas plantas (Marschner, 1995; Krohn et al., 2003; Faquin \& Andrade, 2004; Pôrto et al., 2008). Esse horário de colheita foi escolhido devido a estar compreendido no período em que ocorrem pequenas variações no acúmulo de nitrato pela alface, que é entre 12 e 18 hs (Krohn et al., 2003). Esses menores valores podem ser explicados, também, pela alta intensidade luminosa, que promove maior atividade fotossintética e resulta em maior produção de ferredoxina reduzida nos cloroplastos (cujos elétrons são originados no fotossistema I (FSI) da fase clara da fotossíntese). Essa substância atua como poder redutor para a redução do nitrito a amônio, pela enzima redutase do nitrito (etapa final de redução e assimilação do nitrato), reduzindo o acúmulo de nitrato pelas plantas (Faquin \& Andrade, 2004).

Dessa forma, os resultados obtidos foram abaixo dos níveis permitidos pela União Européia para a alface produzida em ambiente protegido com produções de 3,5 a 4,5 $\mathrm{g} \mathrm{kg}^{-1}$ de matéria fresca (Van Der Boon et al., 1990). Considerando ainda esse fato e partindo do limite máximo aceitável de ingestão diária de nitrato pelo homem $\left(3,7 \mathrm{mg} \mathrm{kg}^{-1}\right.$ de peso vivo) (WHO, 1995) e dos máximos teores foliares obtidos, de forma a desprezar as demais fontes de nitrato, verifica-se que uma pessoa com $70 \mathrm{~kg}$ poderia consumir diariamente até $420 \mathrm{~g}$ de alface produzida nesta condição, quantidades essas bastante acima das estimativas de consumo de uma pessoa normal com essa condição corporal, demonstrando que os valores obtidos não fornecem risco à saúde humana. Esses resultados levam a crer que nas condições do Nordeste brasileiro, mesmo diante do emprego de níveis elevados de $\mathrm{N}$ na solução nutritiva, o acúmulo de nitrato pela 
alface a níveis inadequados ao consumo humano seria pouco provável.

Diante do exposto, pode-se concluir que os níveis de $\mathrm{N}$ estudados não influenciaram o desempenho produtivo da alface, fato que pode estar relacionado com as altas temperaturas observadas no interior da estufa de produção durante o período de cultivo. $\mathrm{O}$ aumento da disponibilidade de $\mathrm{N}$ na solução nutritiva resultou em incremento linear dos teores de nitrato nas diferentes partes da alface, entretanto, os máximos teores foliares de nitrato obtidos se encontraram abaixo do limite de risco para saúde humana.

\section{AGRADECIMENTOS}

Ao CNPq, pela concessão da bolsa de estudo ao primeiro autor.

\section{REFERÊNCIAS}

ADDISCOTT TM; BENJAMIN N. 2004. Nitrate and human health. Soil and Use Manage 20: 98-104.

ANDRIOLO JL. 2000. Fisiologia da produção de hortaliças em ambiente protegido. Horticultura Brasileira 18: 26-33 (Suplemento).

BENINNI ERY; TAKAHASHI HW; NEVES CSVJ; FONSECA ICB. 2002. Teor de nitrato em alface cultivada em sistemas hidropônico e convencional. Horticultura Brasileira 20: 183-186.

BERNARDES LJH. 1997. Hidroponia da alface: uma historia de sucesso. Chaqueada: Est. Experimental de Hidroponia "Alface e Cia". $135 \mathrm{p}$.

BOINK A; SPEIJERS G. 2001. Health effect of nitrates and nitrites, a review. Acta Horticulturae 563: 29-36.

CARON BO; MEDEIROS SLP; MANFRON PA; SCHMIDT D; BIANCHI C; POMMER SF. 2003. Eficiência de conversão da radiação fotossinteticamente ativa interceptada em fitomassa de alface. Revista Brasileira de Agrometeorologia 11: 261-268.

CASAROLI D; FAGAN EB; SANTOS OS; BONNECARRÈRE RAG; NOGUEIRA FILHO H. 2003. Desempenho de onze cultivares de alface em duas formas diferentes de canais de cultivo, no sistema hidropônico. Revista da Faculdade de Zootecnia, Veterinária e Agronomia 10: 114-123.
CATALDO DA; HAROON M; SCHRADER LE; YOUNGS VL. 1975. Rapid colorimetric determination of nitrate in plant tissue by nitration of salicylic acid. Communication in Soil Science and Plant analysis 6: 71-80.

CHEN BM; WANG ZH; LI SX; WANG GX; SONG HX; WANG XN. 2004. Effects of nitrate supply on plant growth, nitrate accumulation, metabolic nitrate concentration and nitrate reductase activity in three leafy vegetables. Plant Science 167: 635-643.

COMETTI NN; MATIAS GCS; ZONTA E; MARY, W; FERNANDES, MS. 2004. Compostos nitrogenados e açúcares solúveis em tecidos de alface orgânica, hidropônica e convencional. Horticultura Brasileira 22: 748-753.

FAQUIN V; ANDRADE AT. 2004. Nutrição mineral e diagnose do estado nutricional de hortaliças. Lavras: UFLA/FAEPE. 88p.

FAQUIN V; FURTINI NETO A. VILELE LAA. 1996. Produção de alface em hidroponia. Lavras: UFLA. 50p.

FAVARO-TRINDADE CS; MARTELLO LS; MARCATTI B; MORETTI TS; PETRUS RR; ALMEIDA E; FERRAZ JBF. 2007. Efeito dos sistemas de cultivo orgânico, hidropônico e convencional na qualidade de alface lisa. Brazilian Journal of Food Technology 10: 111-115.

FERNANDES AA; MARTINEZ HEP; PEREIRA PRG; FONSECA CMM. 2002. Produtividade, acúmulo de nitrato e estado nutricional de cultivares de alface em hidroponia em função de fontes de nutrientes. Horticultura Brasileira 20: 195-2000.

FILGUEIRA FAR. 2008. Novo manual de olericultura. 3. ed. Viçosa: Editora UFV. 421p.

GUALBERTOR; OLIVEIRAPSR; GUIMARÃES AM. 2009. Adaptabilidade e estabilidade fenotípica de cultivares de alface do grupo crespa em cultivo hidropônico. Horticultura Brasileira 27: 007-011.

GÜLSER F. 2005. Effects of ammonium sulphate and urea on $\mathrm{NO}_{3}^{-}$and $\mathrm{NO}_{2}^{-}$accumulation, nutrient contents and yield criteria in spinach. Scientia Horticulturae 106: 330-340.

HOAGLAND DR; ARNON DL. 1938. The water culture methods for growing plants without soil. Berkeley, USA: The College of Agriculture University of California, California Agriculture Station. 32p. (Circular, 347).

KROHN NG; MISSIO RF; ORTOLAN ML; STEINMACHER DA; LOPES MC. 2003. Teores de nitrato em folhas de alface em função do horário de coleta e do tipo de folha amostrada. Horticultura Brasileira 2: 16-219.

LOPES MC; FREIRE M; MATTE JD; GÄRTNER M; FRANZENER G; CASIMIRO ELN;
SEVignANi A. 2003. A. Acúmulo de nutrientes por cultivares de alface em cultivo hidropônico no inverno. Horticultura Brasileira 21: 211-215.

MANTOVANI JR; FERREIRA ME; CRUZ MCP. 2005. Produção de alface acúmulo de nitrato em função da adubação nitrogenada. Horticultura Brasileira 23: 758-762.

MARSCHNER H. 1995. Mineral nutrition of higher plant. New York: Academic Press. $889 \mathrm{p}$.

OHSE S; DOURADO NETO D; MANFRON PA; DURANTE EC. 2002. Composição centesimal, teor de vitamina $\mathrm{C}$ e de nitrato em seis cultivares de alface produzidas em quatro soluções hidropônicas. Insula 31: 59-79.

PÔRTO ML. 2006. Produção, estado nutricional e acúmulo de nitrato em plantas de alface submetidas à adubação nitrogenada e orgânica. 2006. Areia: UFPB-CCA. 66f. (Tese mestrado).

PÔRTO ML; ALVES JC; SOUZA AP; ARAUJO RC; ARRUDA JA. 2008. Nitrate production and accumulation in lettuce as affected by mineral nitrogen supply and organic fertilization. Horticultura Brasileira 26: 227-230.

SAEG. 2007. Sistema para Análises Estatísticas. Versão 9.1. Viçosa: Fundação Arthur Bernardes.

TAKAHASHI HW; HIDALGO PC; FADELLI L; CUNHA MET. 2007. Composição e manejo da solução nutritiva visando à diminuição do teor de nitrato nas folhas de alface hidropônica. Horticultura Brasileira 25: 06-09.

TURAN M; SEVIMLI F. 2005. Influence of different nitrogen sources and levels on ion content of cabbage (Brassica oleracea var. capitata). New Zealand Journal of Crop and Horticultural Science 33: 241-249.

TURAZI CMV; JUNQUEIRAAMR; OLIVEIRA AS; BORGO LA. 2006. Acúmulo de nitrato em alface em função da adubação, horário de colheita e tempo de armazenamento. Horticultura Brasileira 24: 65-70.

VAN DER BOON J; STEENHUIZEN JW; STEINGROVER EG. 1990. Growth and nitrate concentration of lettuce as affected by nitrogen and chloride concentration, $\mathrm{NH}_{4}^{+} /$ $\mathrm{NO}_{3}^{-}$ratio and temperature of the recirculating nutrient solution. Journal of Horticultural Science 65: 309-321.

WIEN HC. 1997. Lettuce. In: WIEN HC (ed). The physiology of vegetable crops. New York: $\mathrm{Cab}$ International. p. 479-509

WORLD HEALTH ORGANIZATION (WHO). 1995. Evaluation of certain food additives and contaminants. (Forty-fourth report of the Joint FAO/WHO Expert Committee on Food Additives). Geneva: FAO/WHO. 54p. (WHO Technical Report Series, 859) 